\title{
Butterfly Pea (Clitoria ternatea) Flower Extract (BPFE) and Its Use as a pH-Dependent Natural Colorant ${ }^{1}$
}

\author{
Sean Michael Campbell, Brian Pearson, and Chris Marble ${ }^{2}$
}

\section{Introduction}

Few traits are as important to the appearance and quality of foods as color; from the deep red of a ripe apple to the electric blue of a sports drink, color is often one of the first sensory qualities of a product that the consumer encounters. Because of this, food manufacturers often add synthetic dyes to their products to simulate or improve desired colors, but research has shown these dyes can be harmful to humans (Chu et al., 2016) and result in hyperactivity in children (McCann et al., 2007).

Because of these concerns, there has been growing interest in the discovery and use of natural colorants, among which blues are rare and tend to be sensitive to processing and storage conditions (Chu et al., 2016). Extracts of the flowers of the butterfly pea (Clitoria ternatea) can serve as a natural blue colorant, tend to be convenient to use, and possess a longer shelf life than comparable plant-based colorants (Siti Azima et al., 2017).

A relatively easily maintained, herbaceous twining vine, the butterfly pea produces deep blue to purple flowers capable of blooming nearly year-round (Park and Knox, 2016). Being drought tolerant and possessing a high growth rate, this popular ornamental is often found wild in its native Asian habitat or cultivated in gardens and landscapes. It also has a deep history as a medicinal herb (Makasana et al., 2017; Rojas-Sandoval, 2018). The flowers, leaves, young shoots and tender pods are all edible and commonly consumed, and the leaves can also be used as a green colorant (Mukherjee et al., 2008).

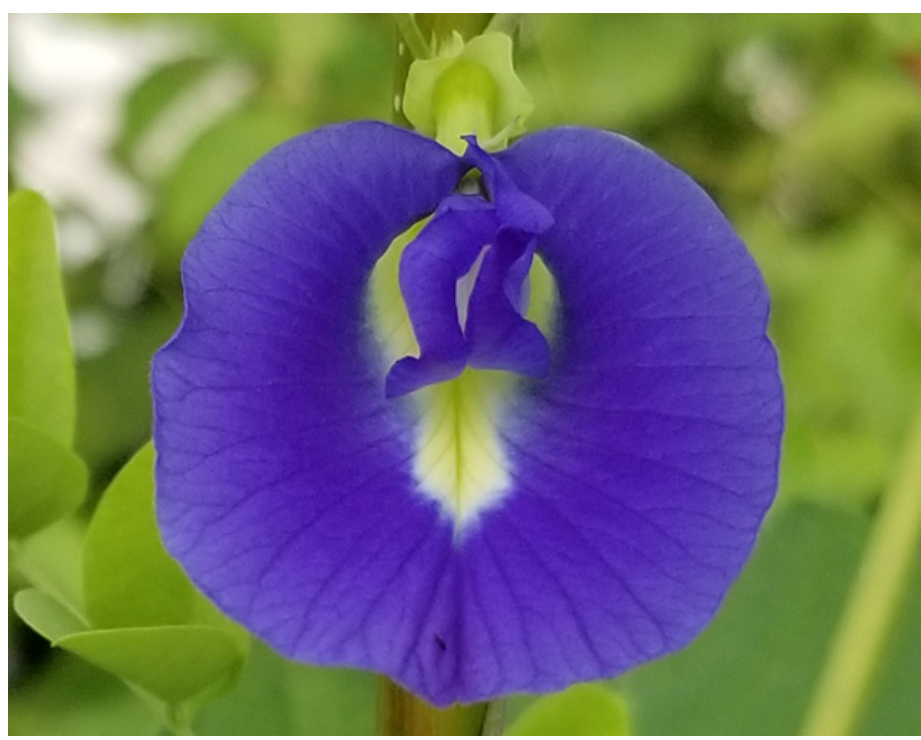

Figure 1. Butterfly pea (Clitoria ternatea) flower.

Credits: Sean M. Campbell, UF/IFAS

Recognizing the need for reliable sources of these natural colorants, the University of Florida Institute of Food and Agricultural Sciences (UF/IFAS) Mid-Florida Research and Education Center (MREC) Medicinal and Beverage Crop program developed this publication as a reference for the extraction, processing and storage of the color-changing natural colorants found in butterfly pea flower extract (BPFE).

1. This document is ENH1309, one of a series of the Environmental Horticulture Department, UF/IFAS Extension. Original publication date April 2019. Visit the EDIS website at https://edis.ifas.ufl.edu for the currently supported version of this publication.

2. Sean Campbell, doctoral research assistant; Brian Pearson, assistant professor; and Chris Marble, assistant professor, Environmental Horticulture Department; UF/IFAS Mid-Florida Research and Education Center, Apopka, FL 32703. 


\section{Color-Changing Anthocyanin}

The largest group of phenolic pigments, anthocyanins, are primarily associated with the antioxidant and colorant properties of the flower or fruit they are in. These same compounds are directly responsible for the blue, purple, pink, red and orange colors found in plants. In butterfly pea flowers, the main anthocyanin responsible for the deep blue to purple color is delphinidin. Siti Azima et al. found that with a significantly higher color density (CD) and chroma (C) value, BPFE has a more intense, vivid and saturated color than other natural colorants they tested.

Also unique to BPFE is the ability of the extract to change color; four different colored forms of the anthocyanin exist, and they can be changed back and forth purely based on the $\mathrm{pH}$. In the flowers, the deep blue to purple color is caused by a near-equal mixture of the flavylium (red) and quinoidal (blue) forms. When the $\mathrm{pH}$ is lowered, usually through the addition of a mild acid like lemon or lime juice, there is more of the flavylium (red) form and the BPFE will appear pink or light purple instead. When the $\mathrm{pH}$ is raised, the quinoidal (blue) and chalcone (yellow) forms are both present, leading to a green color. This is commonly achieved through the addition of the spice saffron due to its alkalinity (Chu et al., 2016). This relationship is demonstrated in Figure 2, with examples in Figure 3.

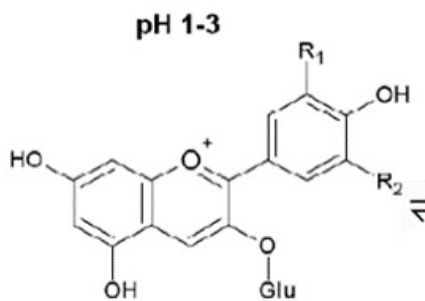

Flavylium cation (red)

।

Chalcone (yellow)

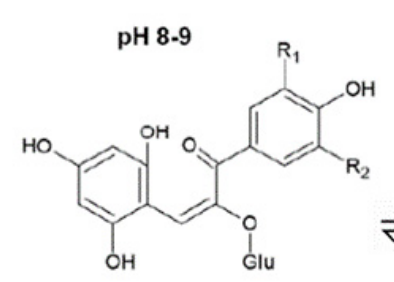

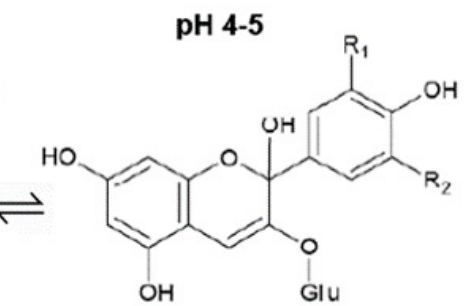

Carbinol pseudobase (colourless)<smiles>[CH]1C=C1</smiles>

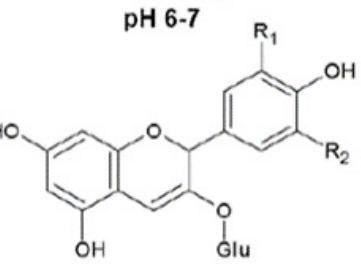

Quinondal base (blue)
Figure 2. The four main forms of anthocyanins at varying $\mathrm{pH}$. Credits: Chu et al. (2016)

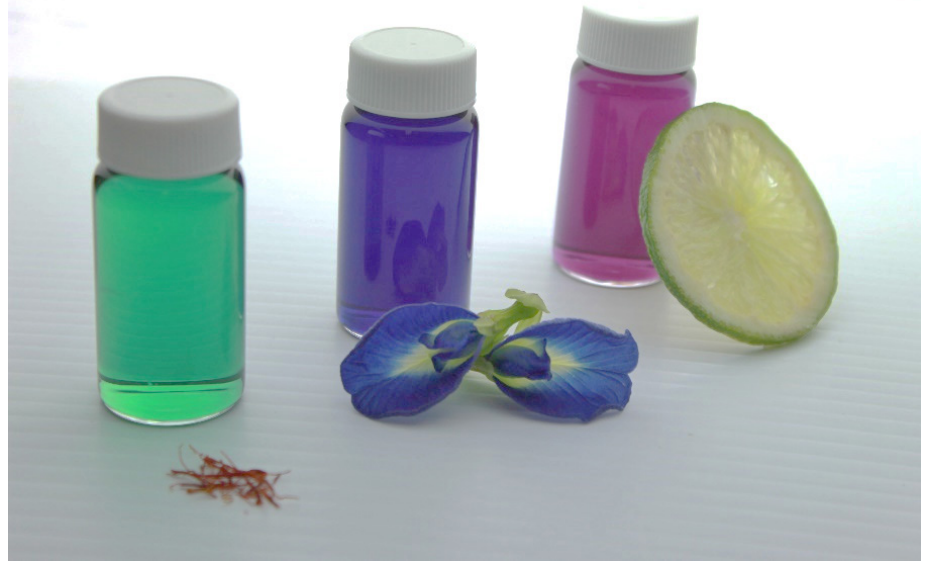

Figure 3. Butterfly pea (Clitoria ternatea) flower extract at normal pH (blue), lowered $\mathrm{pH}$ (purple/pink) and raised pH (green). Credits: Sean M. Campbell, UF/IFAS

\section{Extraction}

In order to utilize the BPFE, the natural colorant must first be extracted from the plant material. A variety of factors affect the overall extractable yield, or the percentage of desired compounds that are derived from original plant material, but the primary ones are the choice of solvent or liquid medium, extraction temperature, extraction duration and the ratio of extractable solids (flowers) to solvent volume. Various procedures exist for the extraction of plant material, and traditionally direct addition of a powdered form of the dried flowers into food is most common. For the purposes of this publication, only procedures that can be safely performed at home on either fresh or dried flowers and that yield an edible liquid extract will be discussed.

\section{Solvent}

At its most basic, plant extraction involves separation of desired portions of the plant material from the inactive or undesired components, primarily through the use of a liquid solvent. In their study looking at extraction parameters on the quality of BPFE, Makasana et al. found that maximum solvent extraction efficiency was achieved by using a hybrid solvent, specifically alcohol mixed into water. Increased contact between the surface area of the plant material and the solvent is caused by a swelling of the plant matrix by the water, which increases the extractability of the alcohol. At 40\% (80 proof), 50\% (100 proof) and $75.5 \%$ (151 proof) alcohol by volume (ABV), respectively, vodka and other higher-proof spirits make appropriate solvents fitting these criteria, depending on the desired final application. High-concentration alcohol, such as 95\% (190 proof) grain alcohol, should be avoided because it does not contain enough water to be an effective solvent. For a 
non-alcoholic alternative, pure water $(0 \% \mathrm{ABV})$ may be used (Figure 4).

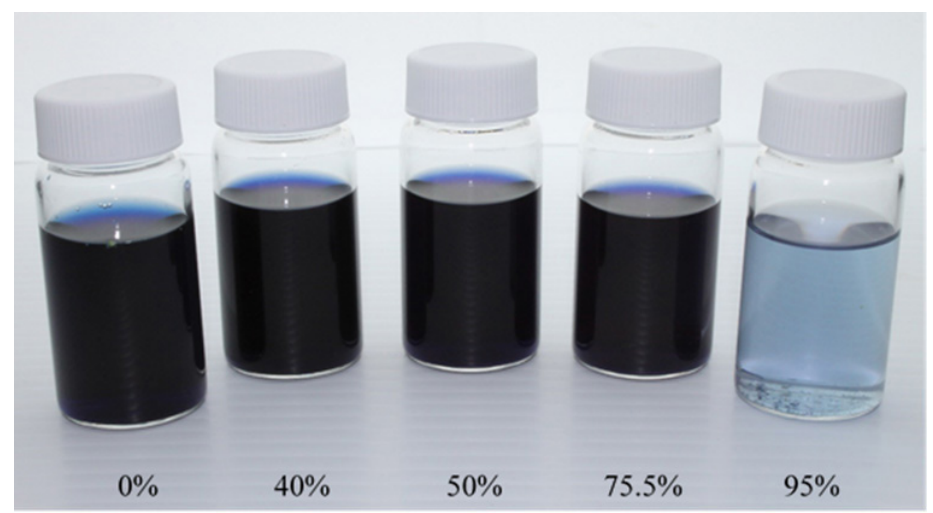

Figure 4. Butterfly pea (Clitoria ternatea) flower extracted in different solvents. Left to right: $0 \%, 40 \%, 50 \%, 75.5 \%$ and $95 \%$ alcohol by volume (ABV) in water. Extraction performed at $175^{\circ} \mathrm{F}\left(\sim 80^{\circ} \mathrm{C}\right)$ for a duration of 60 minutes and at a solid-to-liquid ratio of $1: 20 \mathrm{~g} / \mathrm{mL}$. Credits: Sean M. Campbell, UF/IFAS

\section{Extraction Temperature}

Extraction temperature is also an important factor affecting extractable yield; by assessing a range of different temperatures, the authors were able to determine that extractable yield gradually increases as the temperature is raised from $100^{\circ} \mathrm{F}\left(\sim 40^{\circ} \mathrm{C}\right)$ to $175^{\circ} \mathrm{F}\left(\sim 80^{\circ} \mathrm{C}\right)$, with a maximum at $175^{\circ} \mathrm{F}\left(\sim 80^{\circ} \mathrm{C}\right)$ before declining at higher temperatures. The increase in extraction with increasing temperature is likely due to increased molecular agitation; addition of heat results in more energy, and as the molecules move around more in response to the increased energy, they are more likely to come in contact with the solvent and thus be extracted. Above $175^{\circ} \mathrm{F}\left(\sim 80^{\circ} \mathrm{C}\right)$, the compounds being extracted are damaged by heat, decreasing overall yield. Also, ethanol will boil and vaporize at $173^{\circ} \mathrm{F}\left(\sim 78^{\circ} \mathrm{C}\right)$, which can cause the proportion of alcohol to water to become reduced. Therefore in order to maximize extractable yield, temperatures up to $170^{\circ} \mathrm{F}\left(\sim 77^{\circ} \mathrm{C}\right)$ should be used.

\section{Extraction Duration}

Extraction duration, or more specifically the amount of time the plant material is left in the solvent, is the next important consideration when discussing BPFE extraction efficiency and maximizing extractable yield. Extraction durations of 15 to 150 minutes were tested. Sixty minutes was found to be optimal. Extractions $<60$ minutes produced lower extract yield, whereas extractions $>60$ minutes led to decreased BPFE quality.

\section{Solid-to-Liquid Ratio}

The final consideration when performing BPFE extraction is the ratio of extractable solids to solvent, more commonly referred to as the solid-to-liquid ratio. This is important primarily because it ensures that both ingredients, the butterfly pea flowers as well as the extractable solvent, are used in the most efficient way possible. Studying the extraction process using a series of solid-to-liquid ratios expressed as grams per milliliter $(\mathrm{g} / \mathrm{mL})$ from $1: 5$ to $1: 30$, or $1 \mathrm{~g}$ of flowers to $5 \mathrm{~mL}$ of the solvent for $1: 5$, the authors concluded that the extractable yield increased as the solid-to-liquid ratio was lowered from 1:5 to $1: 20 \mathrm{~g} / \mathrm{mL}$. As the amount of solvent compared to plant material is increased, the solvent's ability to dissolve the plant material is improved, which maximizes the extractable yield. Below 1:20 g/mL the extractable yield no longer increases, so the extra use of solvent makes these solid-to-liquid ratios less efficient and therefore more expensive.

Overall, it is recommended that in order to maximize extractable yield from fresh or dried butterfly pea flowers and yield an edible liquid extract (BPFE) that can be safely produced at home, a hybrid solvent of alcohol in water (i.e., $40 \% \mathrm{ABV}$ ( 80 proof) vodka) should be used at $170^{\circ} \mathrm{F}$ $\left(\sim 77^{\circ} \mathrm{C}\right)$ for a duration of 60 minutes and at a solid-toliquid ratio of 1:20 g/mL (Makasana et al., 2017). While this procedure will produce a BPFE with the highest levels of color-containing compounds, this will often be too strong for most applications, requiring too much acid to be added before the color will change. If this is the case, dilute the BPFE with more solvent until it reaches the desired color and concentration. It should also be noted that when using commercially available spirits as the solvent, some alcohol will likely be consumed in the process and should be done so responsibly and in accordance with state and federal laws.

\section{Storage and Processing}

Once the BPFE has been produced with a maximized extractable yield, several variables affect storage and processing. Given recent concerns about the use of synthetic food colors and their effect on human health, natural blue colorants such as BPFE have become popular alternatives for food manufacturers. Unfortunately, thermal and $\mathrm{pH}$ conditions that natural blue colorants are exposed to during storage and processing often cause them to change colors or flavors in a way that makes them unusable. BPFE tends to be stable to these conditions while maintaining its bright color.

\section{Temperature}

Anthocyanins, such as those found in the BPFE, are sensitive to high heat. Storage of these compounds at 
elevated temperatures leads to increased concentrations of chalcone (yellow), resulting in a faded brown color. This is commonly observed in red wine, another potent source of anthocyanin. Butterfly pea flower extract, on the other hand, has a significantly higher color density (CD) than other natural colorants tested, likely because of high amounts of certain pigment (color) compounds. It is these pigments that also give BPFE its stability during storage and processing in high temperatures.

\section{pH}

As presented earlier, BPFE and its associated anthocyanins are heavily influenced by $\mathrm{pH}$ of the surrounding solution, primarily when it comes to the color of the extract. At its normal $\mathrm{pH}(6.0-8.0)$ the deep blue to purple color is caused by a near equal mixture of the flavylium (red) and quinoidal (blue) forms of anthocyanin; going outside of that normal $\mathrm{pH}$ range can cause undesired color changes in the finished product.

Flour commonly contains bleaching agents such as benzoyl peroxide, which can oxidize and discolor certain anthocyanins, making them unusable in most baked goods. This color change is measured as the indices of polymeric color (PC), or the stability of the colorant towards bisulphite reaction. With a higher $\mathrm{PC}$ than other natural colorants tested, BPFE shows strong potential for being used in applications where it is exposed to storage and processing pH changes (Siti Azima et al., 2017).

\section{Sucrose}

While discussing the effects of storage and processing conditions on the color and quality of BPFE, it is also important to mention the potential protective properties of sucrose, a.k.a. sugar. When sugar is added to the BPFE at its normal $\mathrm{pH}$ and heat is applied, the sucrose molecules take up space in the mixture, binding to the water molecules. The less water that is available, the less damage the heat can do to the anthocyanin. Therefore, the more sugar added, the less water available and the less damage done. This same principle can be applied to $\mathrm{pH}$ changes, though sugar's protective ability is less effective for $\mathrm{pH}$ extremes than temperature. While the addition of sugar does help maintain the BPFE at its normal $\mathrm{pH}$ and associated deep blue to purple color, it is not strong enough to prevent it from changing to pink or green at lower or higher $\mathrm{pHs}$, respectively. So while it does not completely prevent changes, addition of sugar to BPFE can help preserve its color and quality during storage and processing conditions (Chu et al., 2016).

\section{Antioxidant and Other Benefits}

When talking about consuming any plant-based extract, it is also important to discuss the different benefits and effects the associated compounds can have. A major issue for dental health, Streptococcus mutans is a primary cause of dental problems due to its ability to colonize on teeth and form plaque, leading to the development of oral diseases. When applied to these bacteria, a low dose $(0.06 \mathrm{mg} / \mathrm{ml})$ of BPFE effectively inhibited up to $70 \%$ of their growth, showing it has antibacterial capability (Yanti et al., 2018).

A natural part of the metabolic process, the body produces damaging byproducts in the form of reactive oxygen species, or ROS. While normal in regular amounts, excess quantities of these ROS can lead to cancer, cardiovascular disease, diabetes, aging and other ailments. Compounds with antioxidant properties such as anthocyanins have been found to eliminate these ROS, helping to prevent or delay the associated effects (Makasana et al., 2017). Furthermore, it has been shown that consuming small quantities of BPFE can significantly increase the body's natural antioxidant ability, known as plasma antioxidant capacity. When consumed in the presence of sugar, BPFE has been shown to improve post-meal glucose and insulin levels, and diabetic rats that were then fed the BPFE for three weeks had significantly lower serum sugar levels afterwards (Chusak et al., 2018; Mukherjee et al., 2008).

\section{References}

Chu, B.-S., J. Wilkin, M. House, M. Roleska, and M. Lemos, 2016. Effect of Sucrose on Thermal and pH Stability of Clitoria ternatea Extract.

Chusak, C., T. Thilavech, C.J. Henry, and S. Adisakwattana, 2018. Acute effect of Clitoria ternatea flower beverage on glycemic response and antioxidant capacity in healthy subjects: a randomized crossover trial. BMC Complementary and Alternative Medicine 18:6.

Makasana, J., B.Z. Dholakiya, N.A. Gajbhiye, and S. Raju, 2017. Extractive determination of bioactive flavonoids from butterfly pea (Clitoria ternatea Linn.). Research on Chemical Intermediates 43:783-799.

McCann, D., A. Barrett, A. Cooper, D. Crumpler, L. Dalen, K. Grimshaw, E. Kitchin, K. Lok, L. Porteous, E. Prince, E. Sonuga-Barke, J.O. Warner, and J. Stevenson, 2007. Food additives and hyperactive behaviour in 3-year-old and 8/9-year-old children in the community: a randomised, double-blinded, placebo-controlled trial. The Lancet 370:1560-1567. 
Mukherjee, P.K., N.S. Kumar V Fau - Kumar, M. Kumar Ns Fau - Heinrich, and M. Heinrich, 2008. The Ayurvedic medicine Clitoria ternatea--from traditional use to scientific assessment.

Park, B.S. and G.W. Knox, 2016. Flowering Vines for Florida. CIRCULAR 860. Gainesville: University of Florida Institute of Food and Agricultural Sciences. https://edis.ifas.ufl.edu/ mg097

Rojas-Sandoval, J., 2018. Clitoria ternatea (butterfly-pea). Invasive Species Compendium, https://www.cabi.org/isc/ datasheet/55416.

Siti Azima, A.M., A. Noriham, and N. Manshoor, 2017. Phenolics, antioxidants and color properties of aqueous pigmented plant extracts: Ardisia colorata var. elliptica, Clitoria ternatea, Garcinia mangostana and Syzygium cumini. Journal of Functional Foods 38:232-241.

Yanti, Y., T. Setiawan, and B.W. Lay, 2018. Antibacterial, antibiofilm and quorum sensing inhibitory activities of Clitoria ternatea anthocyanin against Streptococcus mutans. International Journal of Infectious Diseases 73:143-144. 